\title{
Investigation of Variable Cross-Sectional Flow Area for an Enhanced Thermo-Hydraulic Performance in Microchannels
}

\author{
Keng Yong Chua*, Kai Xian Cheng, Kim Tiow Ooi \\ School of Mechanical and Aerospace Engineering, Nanyang Technological University \\ 50 Nanyang Avenue, Singapore 639798, Singapore \\ m150140@e.ntu.edu.sg* corresponding author
}

\begin{abstract}
The effect of variable cross-sectional flow area owing to the change in protrusion height along the flow direction, on the thermo-hydraulic performance was studied experimentally. A steady-state study that utilised single-phase water as the working fluid was conducted for Reynolds number range between 1100 and 4400, with a constant heat input of $1000 \mathrm{~W}$ along the microchannel length of $30 \mathrm{~mm}$. Two microchannel configurations, namely (a) contracted cross-sectional flow area and (b) expanded cross-sectional flow area, were investigated together with a plain microchannel to evaluate the thermo-hydraulic performance. The average hydraulic diameters of the annular microchannels are kept constant at $600 \mu \mathrm{m}$ for both configurations. The microchannel with an expanded cross-sectional flow area yielded the highest Nusselt number of 49.6 at Reynolds number of 4377 . The same microchannel achieved the highest thermo-hydraulic performance index of 1.59 at Reynolds number of 1974 , using the plain microchannel as the reference.
\end{abstract}

Keywords: Annular, Enhance, Heat Transfer, Protrusion Height, Single-Phase, Single-Walled.

\section{Introduction}

Decades of studies have verified microscale heat transfer as a promising heat removal technique. Conventional heat transfer enhancement techniques have been proven to be effective in the microscale gap [1]. However, the small length scale and complexity in the fabrication of microchannels restricted the application of conventional passive heat transfer enhancements to flow disruptions, secondary flows, surface treatments and entrance effects. Among these techniques, flow disruptions are frequently employed in microchannels as they can be easily achieved by implementing surface modifiers, such as protrusions, fins, grooves, wavy and ribs. The downside of implementing these surface modifiers is the pressure drop penalty across the microchannel.

While the increment of pressure drop is unavoidable with the heat transfer enhancement, geometrical parameters and microchannel configurations can be optimised to mitigate the penalty of pressure drop. The size, length, height, compactness and arrangement of fins and protrusions have been extensively investigated to achieve the optimal heat transfer performance with minimal pressure drop penalty [2-7]. The aforementioned geometrical parameters have been studied with good understanding on the underlying mechanisms.

The present study is an extension of the previous study by Cheng and Ooi [7]. They conducted a study on a series of protrusions which yielded a uniform cross-sectional flow area along the flow direction, for three different protrusion heights. Even though the highest protrusions attained the highest heat transfer enhancement, the heat transfer enhancement was insufficient to account for the increment in pressure drop. Therefore, they concluded that there is no single protrusion height that can perform optimally under all operating conditions.

To further explore the effect of protrusion height, this study progresses to investigate the effect of variable crosssectional flow area that results from a variable protrusion height along the flow direction, on the thermal and hydrodynamic performance of the microchannels.

\section{Research Methodology}

\subsection{Plain Microchannel}

The methodology of implementing the microchannels is similar to the one adopted by [7-12]. A solid cylindrical insert with an external diameter of $19.4 \mathrm{~mm}$ is superimposed concentrically within a hollow cylindrical pipe with an internal diameter of $20 \mathrm{~mm}$, yielding an annular gap of $300 \mu \mathrm{m}$ as shown in Fig. 1. The microchannel, configured with a plain insert, is used as a reference for comparison. 


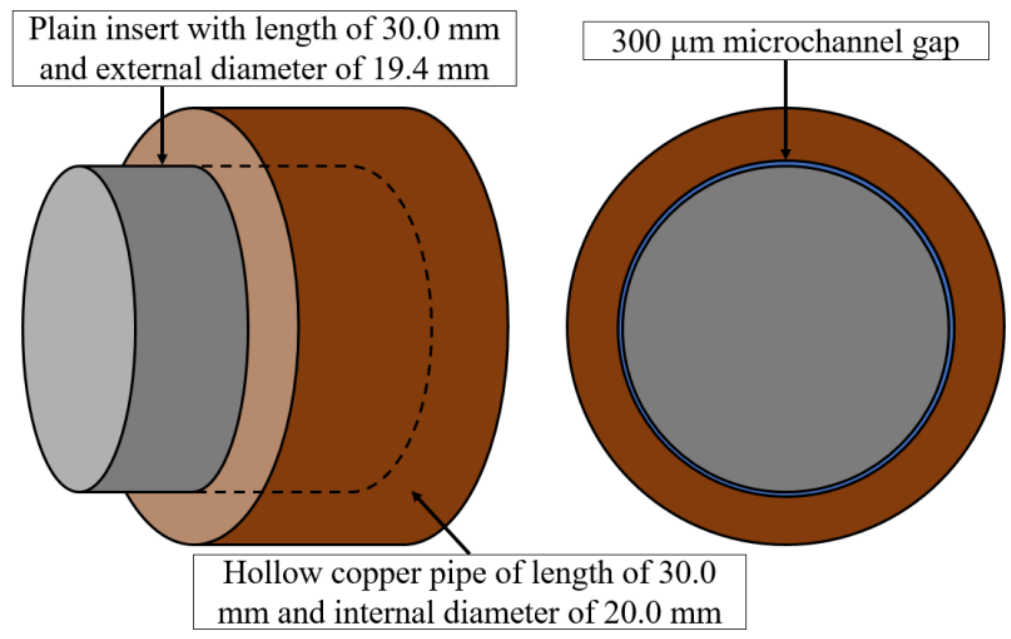

Fig. 1: Plain microchannel.

\subsection{Enhanced Microchannels}

Two cylindrical inserts are fabricated with V-shaped protrusions as shown in Fig. 2. The microchannels are categorised into two zones of equal length along the flow direction. These zones consist of protrusions with different heights, resulting in a change in the cross-sectional flow area along the flow direction. The heights are being increased and reduced in the microchannel named V-CFA and V-EFA respectively. The former results in a contracted crosssectional flow area and vice versa in the latter, as illustrated in Fig. 3 and Fig. 4 respectively. The average gap size of the microchannels is kept constant at $300 \mu \mathrm{m}$.

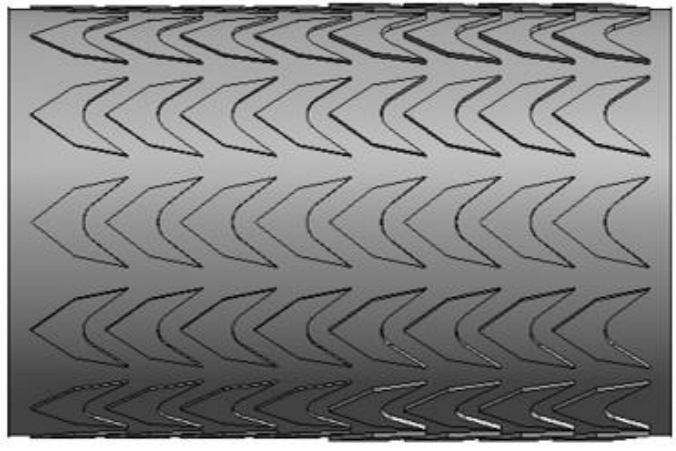

(a)

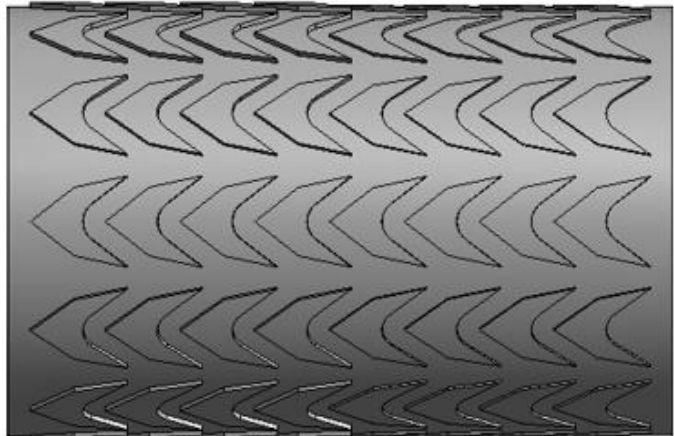

(b)

Fig. 2: (a) V-CFA insert and (b) V-EFA insert.

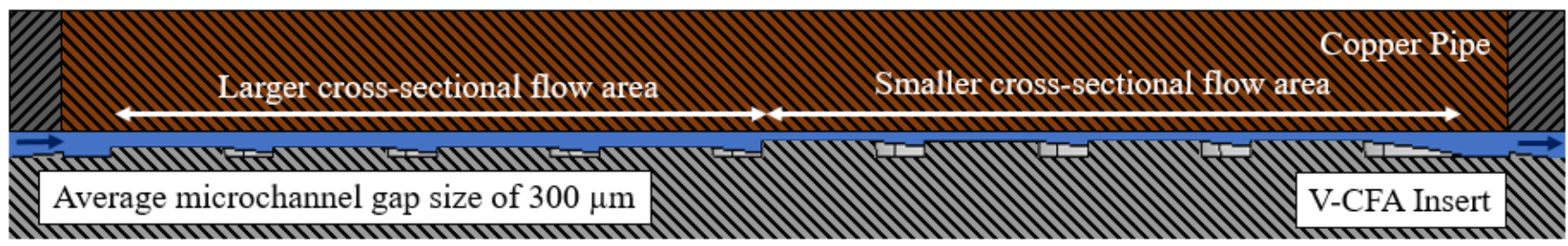

Fig. 3: Cross-sectional view of V-CFA microchannel.

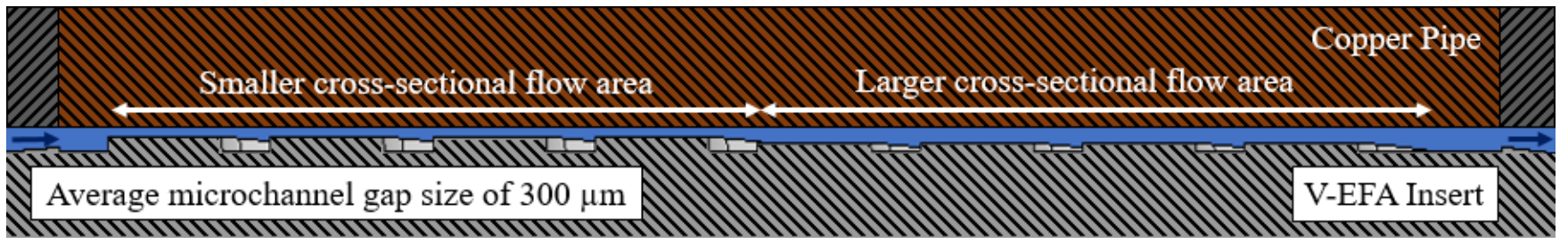

Fig. 4: Cross-sectional view of V-EFA microchannel. 


\section{Experimental System}

The main components in the main test loop are the integrated chiller unit, tee-type filter, bypass valve, type-T thermocouples, pressure transducers, heat supply system, test module, flow meter and needle valve. A schematic drawing of the experimental setup is shown in Fig. 5.

Distilled water is stored in the reservoir of the integrated chiller unit. The integrated chiller unit cools the water to the desired inlet temperature and pumps it into the flow loop. A 40 microns tee-type filter is used to remove the contaminants before the water is channelled into the test module. A bypass valve and a needle valve are used to control the flow rate that enters the test module. A Coriolis flowmeter is positioned downstream to measure the flow rate of the distilled water. The flow is then being channelled back to the reservoir.

One type-T thermocouple and one pressure transducer are positioned at the inlet and outlet of the test module to measure the local fluid temperature and pressure respectively. A Data Acquisition System (DAQ) with LabView software is employed to process the signals collected from the flow meter, thermocouples and pressure transducers.

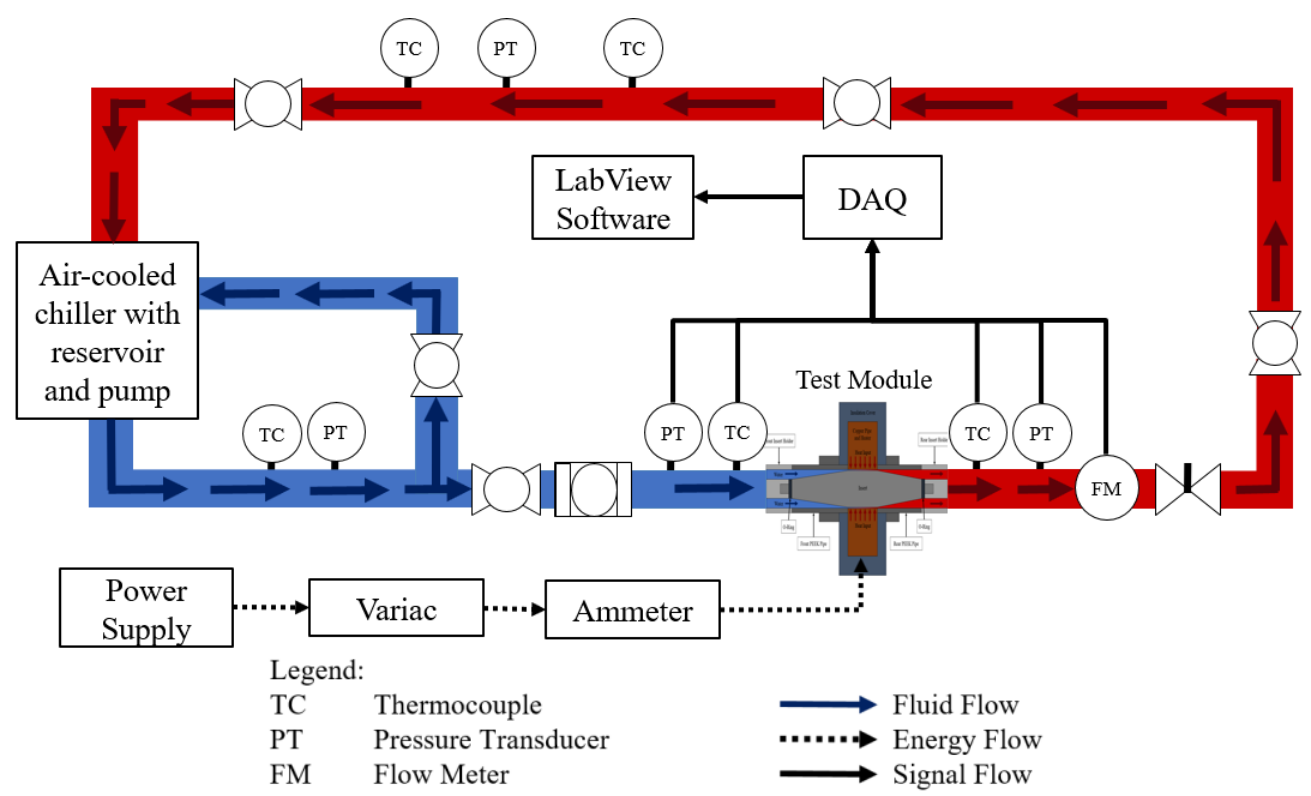

Fig. 5: Experimental flow loop.

\subsection{Test Module}

The test module is shown in Fig. 6. The components are covered by the insulation cover and insulation foam (not shown in the figure) to prevent heat loss to the surrounding. The heater embedded in the copper pipe generates heat that is being absorbed by the water through the microchannel. Ten type-J thermocouples (not shown in the figure) are spaced evenly in the copper pipe to measure the localised temperature of the heat transfer surface.

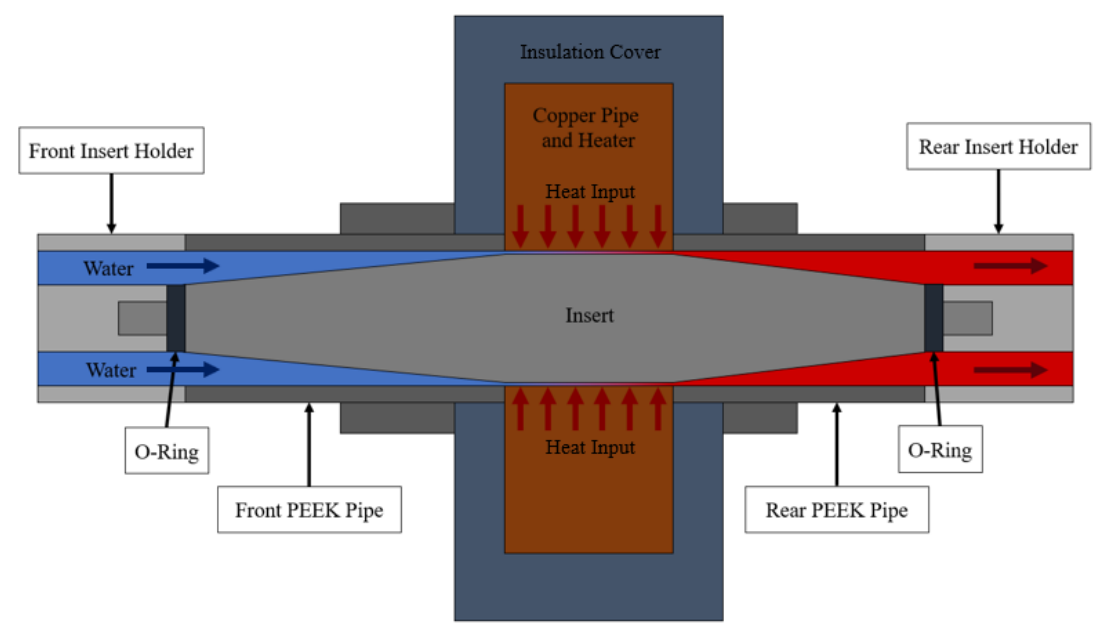

Fig. 6: Test module. 


\subsection{Experimental Conditions}

The study is conducted at a volumetric flow rate from $2.0 \mathrm{~L} / \mathrm{min}$ to $8.0 \mathrm{~L} / \mathrm{min}$, with an interval of $0.5 \mathrm{~L} / \mathrm{min}$, which corresponds to the Reynolds number from 1100 to 4400 . The heat supply to the copper pipe is kept constant at $1000 \mathrm{~W}$ with a constant heat transfer surface area of $18.85 \mathrm{~cm}^{2}$ as the protrusions are introduced on the non-heated surface. Steady-state experimental measurements are recorded for the V-CFA microchannel, V-EFA microchannel and plain microchannel.

\subsection{Data Acquisition and Reduction}

A total of 600 steady-state measurements are recorded at a frequency of $1 \mathrm{~Hz}$ for each experimental run and the average of the steady-state measurements are used for data reduction. The properties of the fluid are extracted from a REFPROP software [13] at the average fluid temperature.

\subsubsection{Heat Transfer Considerations}

The heat energy gained by the fluid per unit time is calculated as shown in Eq. (1).

$$
Q=\rho c \dot{V}\left(T_{o}-T_{i}\right)
$$

The average fluid temperature is determined by the average of the inlet and outlet temperature using Eq. (2).

$$
T_{f, m}=\frac{T_{o}+T_{i}}{2}
$$

The wall temperature is the average of ten thermocouple readings as shown in Eq. (4) after considering the conductive resistance of the copper pipe using Eq. (3), as these devices are positioned at a distance of $2.5 \mathrm{~mm}$ from the copper wall.

$$
\begin{gathered}
T_{w, i}=T_{r=2.5 m m, i}-Q \frac{\ln \left(D_{r} / D_{w}\right)}{2 \pi L k_{c}} \\
T_{w, m}=\sum_{i=1}^{10} \frac{T_{w, i}}{10}
\end{gathered}
$$

Newton's law of cooling is applied to calculate the average heat transfer coefficient as shown in Eq. (5).

$$
h=\frac{Q}{A\left(T_{w, m}-T_{f, m}\right)}
$$

The average Nusselt number is determined using Eq. (6).

$$
N u=\frac{h D_{h}}{k_{f}}
$$

\subsubsection{Hydrodynamic Considerations} (7).

The fluid pressure drop is obtained from the difference between the fluid inlet and outlet pressure as shown in Eq.

$$
\Delta P=P_{i}-P_{o}
$$


The average Darcy friction factor and Reynolds number for the annular microchannel are calculated from Eq. (8) and Eq. (9) respectively.

$$
\begin{gathered}
f=\frac{\Delta P}{(1 / 2) \rho u_{m}^{2}} \cdot \frac{D_{h}}{L}=\frac{\Delta P}{\operatorname{Re}^{2}}\left(\frac{2 D_{h}^{3}}{L} \cdot \frac{\rho}{\mu^{2}}\right) \\
\operatorname{Re}=\frac{4 \rho \dot{V}}{\pi \mu\left(D_{o}+D_{i}\right)}
\end{gathered}
$$

\subsubsection{Thermo-Hydraulic Performance}

The thermo-hydraulic performance index, suggested by Webb [14], is computed as shown in Eqn. (10). The performance index has been widely used to evaluate the relative thermo-hydraulic performance [15-16].

$$
\eta=\left(\frac{N u}{N u_{\text {Plain }}}\right) /\left(\frac{f}{f_{\text {Plain }}}\right)^{\frac{1}{3}}
$$

\subsection{Uncertainty Analysis}

The maximum uncertainty of the key parameters is presented in Table 1.

Table 1: Maximum experimental uncertainties.

\begin{tabular}{|c|c|}
\hline Parameter & Maximum uncertainty (\%) \\
\hline$R e$ & 0.7 \\
\hline$N u$ & 11.6 \\
\hline$f$ & 2.0 \\
\hline$\eta$ & 19.5 \\
\hline
\end{tabular}

\section{Results and Discussion}

\subsection{Repeatability Test}

Repeatability test is performed on each microchannel to evaluate the discrepancies in the recorded measurements under the same operating conditions. The repeated measurement is carried out once for each microchannel at a randomly chosen flow rate. The Nusselt number and friction factor are used as the key parameters to monitor the repeatability. The results of the repeatability test are tabulated in Table 2. The discrepancies in Nusselt number and friction factor are way below the experimental uncertainties. Therefore, the repeatability test verifies that the measurements are repeatable.

Table 2: Repeatability test.

\begin{tabular}{|c|c|c|c|}
\hline Microchannel & $\begin{array}{c}\text { Flow Rate } \\
(\mathbf{L} / \mathbf{m i n})\end{array}$ & $\begin{array}{c}\text { Discrepancy in Nusselt } \\
\text { Number (\%) }\end{array}$ & $\begin{array}{c}\text { Discrepancy in } \\
\text { Friction Factor (\%) }\end{array}$ \\
\hline V-CFA & 5.5 & 0.54 & 0.25 \\
\hline V-EFA & 6.0 & 1.41 & 0.16 \\
\hline
\end{tabular}

\subsection{Heat Transfer Consideration}

Fig. 7 shows the Nusselt number against Reynolds number of plain microchannel, V-CFA microchannel and V-EFA microchannel. The Nusselt number increases proportionally with the increase in Reynolds number for all the microchannels, with the V-EFA microchannel attaining the highest Nusselt number of 49.6 at Reynolds number of 4377.

For the plain microchannel, a change in gradient of the trend line is observed between the Reynold number range from 3000 to 3500 . The sharp increase in gradient beyond Reynolds number of 3500 indicates a transition in flow regime, from laminar to turbulent or transitional flow. 
Unlike the plain microchannel, both V-CFA microchannel and V-EFA microchannel exhibit similar trend behaviour with no indication of laminar-to-turbulent transition. It is likely that the flow in both microchannels transits from laminar flow at Reynolds number as low as 1170 .

Additionally, the increment in the Nusselt number of V-EFA microchannel, with respect to V-CFA microchannel, indicates the effect of variable cross-sectional flow area in microchannels. With reference to Cheng and Ooi [7], Nusselt number increases as the cross-sectional flow area decreases. The difference in Nusselt number between both enhanced microchannels implies that the axial position of the protrusions in microchannel has significant impacts on the Nusselt number, even though the average gap size is kept constant.

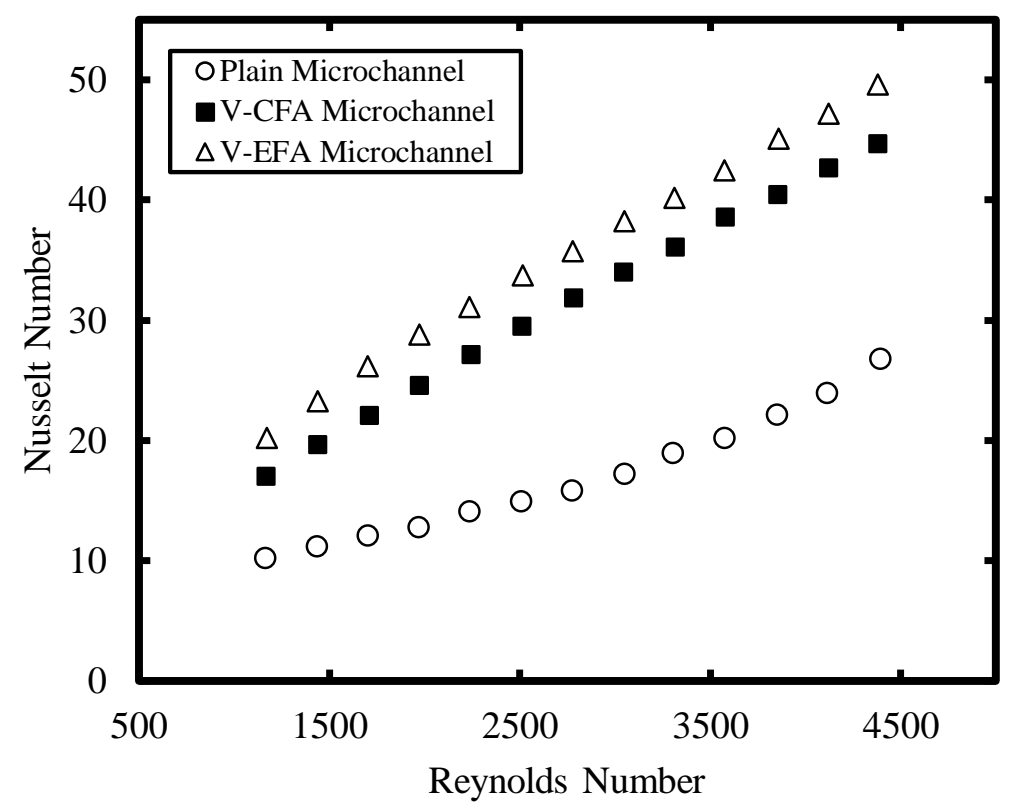

Fig. 7: Nusselt number against Reynolds number of plain microchannel, V-CFA microchannel and V-EFA microchannel.

\subsection{Hydrodynamic Consideration}

Fig. 8 shows the friction factor against Reynolds number of all the microchannels. At Reynolds number of 1170, plain microchannel yielded a friction factor of 0.105 while V-EFA microchannel achieved the highest friction factor of 0.282. Both enhanced microchannels have a constant increment of approximately three times as compared to the plain microchannel. The considerable difference in friction factor is expected as the protrusions in V-CFA microchannel and V-EFA microchannel induce additional flow resistance. Furthermore, small fluid flow gap between the copper wall and the protrusions causes a higher velocity gradient than the plain microchannel. The high-velocity gradient incurs additional shear stress which contributes to the increment in friction factor.

Interestingly, though the configuration of cross-sectional flow area is reversed for V-CFA microchannel and V-EFAmicrochannel, both microchannels have a comparable friction factor. This could indicate that the cross-sectional flow area, particularly the gap formed between the copper wall and the protrusions, has greater significance on the friction factor than the axial position of the protrusions. 


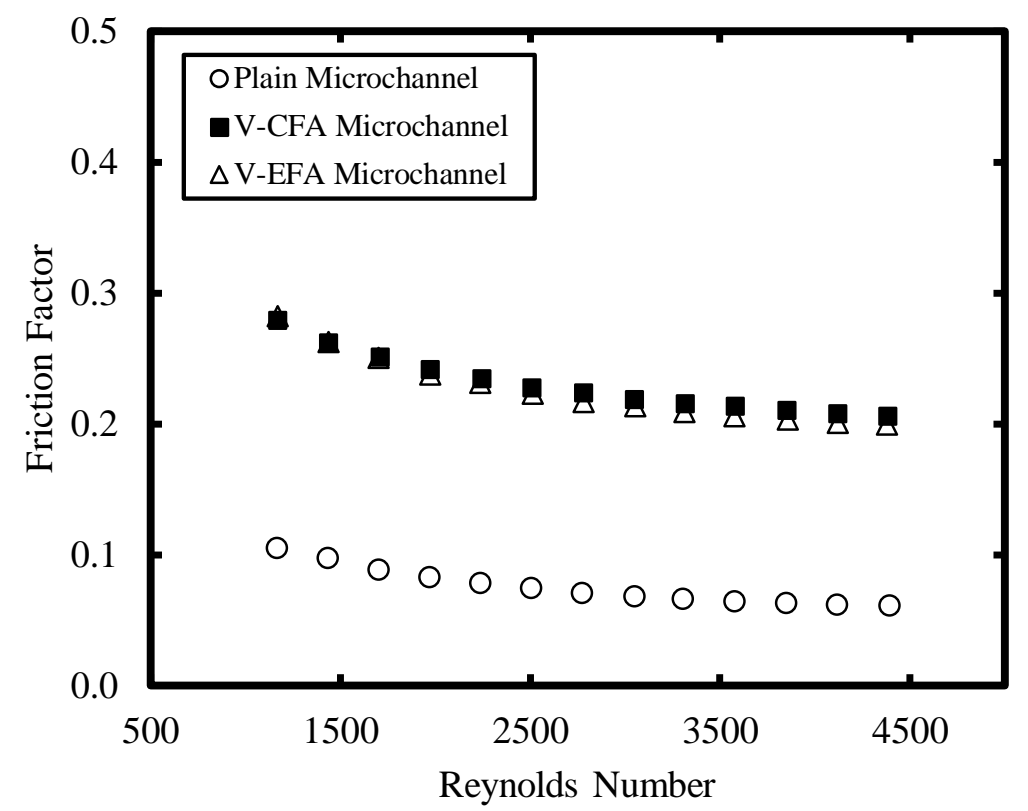

Fig. 8: Friction factor against Reynolds number of plain microchannel, V-CFA microchannel and V-EFA microchannel.

\subsection{Thermo-Hydraulic Performance}

From Fig. 9, it can be concluded that V-EFA microchannel exhibited better thermo-hydraulic performance as compared to V-CFA microchannel for the range of Reynolds number from 1100 to 4400, with the V-EFA microchannel achieving the highest heat transfer performance index of 1.59 at the Reynolds number of 1974.

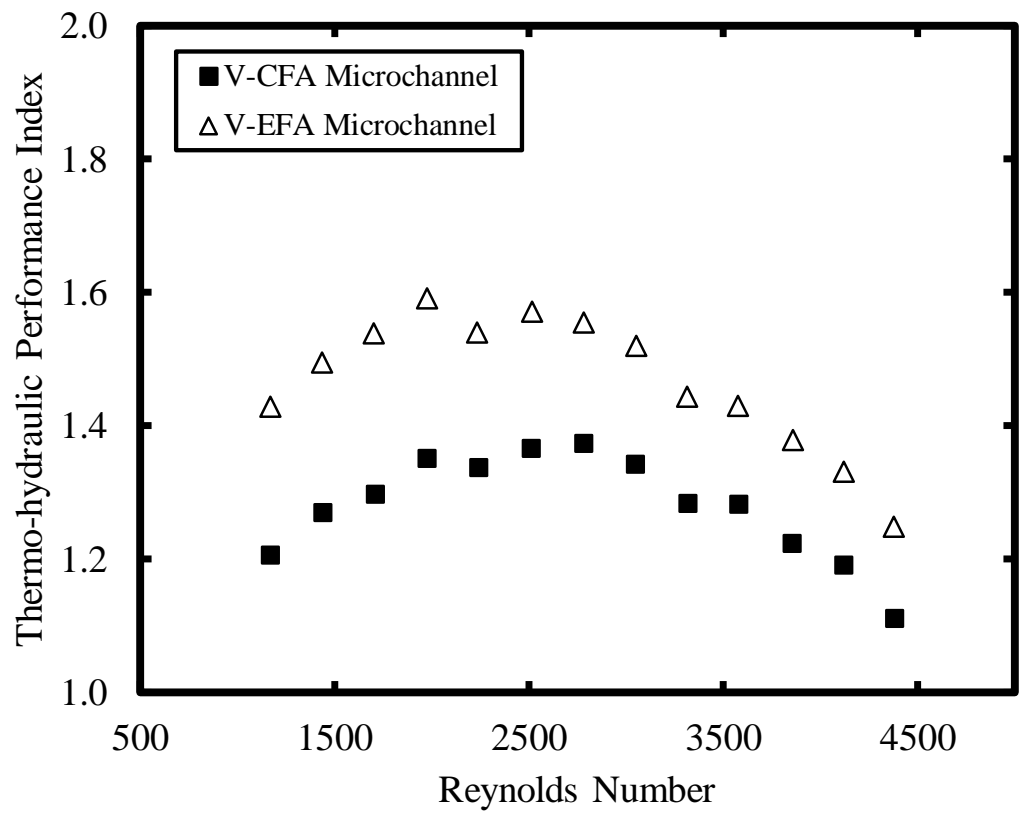

Fig. 9: Thermo-hydraulic Performance Index against Reynolds Number of V-CFA Microchannel and V-EFA Microchannel.

\section{Conclusion}

Two enhanced microchannels with different configurations of cross-sectional flow area were fabricated to investigate the thermo-hydraulic effect of variable cross-sectional flow area. The experiment was conducted under singlephase steady-state condition for Reynolds number from 1100 to 4400. Significant findings from the study include:

(1) The enhanced microchannels achieved a higher Nusselt number than the plain microchannel for all the experimented Reynolds numbers. Furthermore, for all the experimented Reynolds number, the V-EFA microchannel attained a higher Nusselt number than the V-CFA microchannel, with the V-EFA microchannel achieving the highest 
Nusselt number of 49.6 at Reynolds number of 4377. This indicates that the axial position of the protrusions in microchannel affects the overall Nusselt number.

(2) The enhanced microchannels yielded a higher friction factor than the plain microchannel for all the experimented Reynolds numbers, with V-EFA microchannel yielding the highest friction factor of 0.282 at the Reynolds number of 1170. The friction factors of V-CFA microchannel and V-EFA microchannel are comparable at the same Reynold number. It might be due to the fact that the minimum flow area formed between the protrusions and the copper wall has greater significance on the friction factor than the axial position of the protrusions.

(3) The V-EFA microchannel achieved the highest thermo-hydraulic performance index of 1.59 at Reynolds number of 1974. Although the friction factor of V-CFA microchannel and V-EFA microchannel are comparable, the difference in Nusselt number results in the higher thermo-hydraulic performance index of V-EFA microchannel than VCFA microchannel.

\section{Acknowledgements}

The authors would like to express their deepest gratitude to Nanyang Technological University (NTU), Singapore for the financial support. They are also grateful to the lab technicians at Energy Systems Laboratory and Manufacturing Laboratory, School of Mechanical and Aerospace Engineering, NTU, for their technical support.

\section{Nomenclature}

$\begin{array}{cl}A & \text { Heat transfer area }\left(\mathrm{m}^{2}\right) \\ c & \text { Specific heat capacity }\left(\mathrm{J} \mathrm{kg}^{-1} \mathrm{~K}^{-1}\right) \\ D & \text { Diameter }(\mathrm{m}) \\ f & \text { Friction factor (-) } \\ h & \text { Average heat transfer coefficient }\left(\mathrm{W} \mathrm{m}^{-2} \mathrm{~K}^{-1}\right) \\ k & \text { Thermal conductivity }\left(\mathrm{W} \mathrm{m}^{-1} \mathrm{~K}^{-1}\right) \\ L & \text { Channel length (m) } \\ N u & \text { Nusselt number (-) } \\ P & \text { Pressure }(\mathrm{Pa}) \\ Q & \text { Rate of heat transferred }(\mathrm{W}) \\ R e & \text { Reynolds number }(-) \\ T & \text { Temperature }(\mathrm{K}) \\ u & \left.\text { Velocity (m s } \mathrm{s}^{-1}\right) \\ \dot{V} & \text { Volumetric flow rate }\left(\mathrm{m}^{3} \mathrm{~s}^{-1}\right)\end{array}$

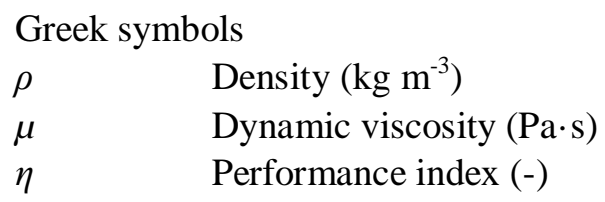

Subscripts

$\begin{array}{ll}c & \text { Copper } \\ f & \text { Fluid } \\ h & \text { Hydraulic } \\ i & \text { Inlet } \\ m & \text { Mean } \\ o & \text { Outlet } \\ r & \text { Radial } \\ w & \text { Wall }\end{array}$

\section{References}

[1] M. E. Steinke, and S. G. Kandlikar, "Single-Phase Heat Transfer Enhancement Techniques in Microchannel and Minichannel Flows," ASME 2nd International Conference on Microchannels and Minichannels, 2004.

[2] F. Hong and P. Cheng, "Three dimensional numerical analyses and optimization of offset strip-fin microchannel heat sinks," International Communications in Heat and Mass Transfer, vol. 36, no. 7, pp. 651-656, 2009.

[3] A. J. L. Foong, N. Ramesh, and T. T. Chandratilleke, "Laminar convective heat transfer in a microchannel with internal longitudinal fins," International Journal of Thermal Sciences, vol. 48, no. 10, pp. 1908-1913, 2009.

[4] Y. J. Lee, P. K. Singh, and P. S. Lee, "Fluid flow and heat transfer investigations on enhanced microchannel heat sink using oblique fins with parametric study," International Journal of Heat and Mass Transfer, vol. 81, pp. 325336, 2015.

[5] A. Koşar and Y. Peles, "Thermal-Hydraulic Performance of MEMS-based Pin Fin Heat Sink," Journal of Heat Transfer, vol. 128, no. 2, pp. 121-131, 2005.

[6] H. Shafeie, O. Abouali, K. Jafarpur, and G. Ahmadi, "Numerical study of heat transfer performance of singlephase heat sinks with micro pin-fin structures," Applied Thermal Engineering, vol. 58, no. 1, pp. 68-76, 2013.

[7] K. X. Cheng and K. T. Ooi, "Investigation of Effect of Protrusion Height on Microscale Heat Transfer and Fluid Flow in Macro Geometries," Applied Thermal Engineering, vol. 118, pp. 244-255, 2017.

[8] K. S. Kong and K. T. Ooi, "A numerical and experimental investigation on microscale heat transfer effect in the combined entry region in macro geometries," International Journal of Thermal Sciences, vol. 68, p. 8-19, 2013.

[9] A. L. Goh and K. T. Ooi, "Nature-inspired Inverted Fish Scale microscale passages for enhanced heat transfer," International Journal of Thermal Sciences, vol. 106, pp. 18-31, 2016. 
[10] A. L. Goh and K. T. Ooi, "Scale-inspired enhanced microscale heat transfer in macro geometry," International Journal of Heat and Mass Transfer, vol. 113, pp. 141-152, 2017.

[11] K. X. Cheng, Y. S. Chong, and K. T. Ooi, "Thermal-hydraulic performance of a tapered microchannel," International Communications in Heat and Mass Transfer, vol. 94, pp. 53-60, 2018.

[12] Z. H. Foo, K. X. Cheng, A. L. Goh and K. T. Ooi, "Single-phase convective heat transfer performance of wavy microchannels in macro geometry," Applied Thermal Engineering, vol. 141, pp. 675-687, 2018.

[13] E. W. Lemmon, M. L. Huber, M. O. McLinden, NIST reference fluid thermodynamic and transport propertiesREFPROP. 2002.

[14] R. L. Webb, "Performance evaluation criteria for use of enhanced heat transfer surfaces in heat exchanger design," International Journal of Heat and Mass Transfer, vol. 24, no. 4, pp. 715-726, 1981.

[15] A. E. Momin, J. S. Saini, S. C. Solanki, "Heat transfer and friction in solar air heater duct with V-shaped rib roughness on absorber plate," International Journal of Heat and Mass Transfer, vol. 45, no. 16, pp. 3383-3396, 2002.

[16] S. C. Lau, R. T. Kukreja, and R. D. Mcmillin, "Effects of V-shaped rib arrays on turbulent heat transfer and friction of fully developed flow in a square channel," International Journal of Heat and Mass Transfer, vol. 34, no. 7, pp. 1605-1616, 1991. 